\title{
The Effectiveness of Incentive Spirometry \\ Training During the Physiotherapy Management of Atelectasis: A Case Report
}

\author{
Monisha $\mathrm{R}^{1}$, TS Muthukumar ${ }^{2 *}$ and K Amutha ${ }^{2}$ \\ ${ }^{1}$ Assistant Professor, SRM College of Physiotherapy, India \\ ${ }^{2}$ Professor, Sri Ramakrishna College of Physiotherapy, India
}

Submission: June 01, 2018; Published: July 18, 2018

*Corresponding author: TS Muthukumar, Professor, Sri Ramakrishna College of Physiotherapy, India, Email: muthukumarphysio@gmail.com

Abstract

Atelectasis is commonly reported as one of the post operative complication in patients with lung and abdominal surgeries. If the post operative complications are left untreated after the surgery, it can lead to infections and fibrosis at later stage. The effectiveness of incentive spirometer training in addition to the respiratory physiotherapy management can help prevent atelectasis and it is one of the gold standard methods in reducing the post operative lung complication and helps re-expand the collapsed lung, there by improves oxygenation and helps to clear the airways. This case report was done to find out the effectiveness of incentive spirometer as a expiratory and inspiratory muscle trainer managing patients with post operative lung complication.

Keywords: Atelectasis; Postural drainage; Respiratory physiotherapy; Incentive spirometer

\section{Introduction}

Pulmonary complications are common in patients with pre-operative respiratory complications. However, previous researchers have emphasized the importance of pre-operative respiratory physiotherapy in the management of post operative lung complications.

But the importance of incentive spirometer training as a inspiratory and expiratory muscle training source has not paid much attention by the researchers and also its beneficial effects in the pre-operative and post operative respiratory physiotherapy management has not been done in the patients receiving bedside physiotherapy treatment in the daily routine. Atelectasis is more common among patients undergoing abdominal and lung surgeries without receiving the pre-operative respiratory therapy. They have a reduction in FRC, ventilation-perfusion mismatching is more pronounced in patients presented in the post operative day 1 . If incentive spirometer training has not been delivered in patients with lung complication.

Several research protocols have been published evaluating the role of physio-therapist in the intensive care unit (ICU). The primary objective of physiotherapy management in ICU is to prevent respiratory complications and to oxygenation. The effectiveness of incentive spirometer training in addition to respiratory physiotherapy management re-inflate collapsed lung and it also aids in removal of secretions. But none of the researcher have highlighted the importance of expiratory muscle training with the help of incentive spirometer.

\section{Literature search}

Incentive spirometric is a device which provides a greater airway clearance and helps in improving oxygenation. This device assists in inflating the lungs with oxygen. Post transplantation procedures and post operative patients in ICU and patients underwent abdominal surgery have limitation in taking a deep breath, because of pain. Incentive spirometer training successfully recruits atelectasis lung segments by proving a resistance to inspiratory component of breathing. This is followed by an inspiratory pause of 2 seconds and a expiratory component has been trained by reversing this device. Leading to a rapid flow of air and it will simulate the cough.

\section{Case History}

A 44-year old male was admitted to the department of pulmonary medicine, on $1 / 09 / 2015$, after diagnosed with exacerbation of COPD. He sustained severe dyspnoea in relation to BORG scale with resultant skeletal muscle dysfunction. Presented with Pectus excavatum and have right side- scoliosis, Chest examination revealed the patient has emphysematic bullae. 
No referral was made to physiotherapy at this time of admission. 2 weeks after admission the patient's respiratory complications were high and he suddenly developed severe respiratory distress. The patient was intubated and his $\mathrm{x}$ ray shows atelectasis in right and left lung lobes.

\section{Examination}

Following physiotherapy referrel, examination of the chest $\mathrm{x}$-ray revealed a total collapse of the right and left lung with the endotracheal tube situated at level T2, his ABG results shows hypoxaemia and respiratory acidosis.

The ventilation parameters were set at peak airway pressure of $35 \mathrm{~cm} \mathrm{H}_{2} \mathrm{O}$, positive end-expiratory pressure (PEEP) of $10 \mathrm{~cm}$ $\mathrm{H}_{2} \mathrm{O}$, pressure support of $20 \mathrm{~cm} \mathrm{H}_{2} \mathrm{O}$ and a ventilation rate of 20 breaths/min and he was in pressure support mode. The patient was in supine lying and Chest wall expansion has been assessed, shows asymmetry in expansion with no expansion on the right side as compared to left.

\section{Intervention}

The first physiotherapy treatment session started at 9.00am. The patient was positioned in left side lying, maintaining the head elevation at $40^{\circ}$. Chest physiotherapy was applied to the posterior and lateral segments of the right lung for 5 minutes and the same maneuver has been repeated for left lung with the patient positioned in right side lying. Thereafter incentive spirometer training was performed by the patient and expiratory muscle training was done followed by inspiratory training with resistance provided in 600, 900 and $1200 \mathrm{cc}$. components of respiratory training circuit. Respiratory muscle training was continued for 10 minutes. Then the therapist applied chest wall shaking to the posterior and lateral lung segments during expiration to facilitate optimal secretion clearance. The treatment session lasted for 20 minutes and no changes in cardiovascular status were noted throughout the treatment.

\section{Outcome}

The assessment after the first treatment revealed that chest wall expansion of right lung had improved significantly but reduced expansion was still present in the left lung. Auscultation revealed improved breath sounds in the right and left lower lobes.

The arterial blood gas results taken at 10:00,12:00 and 16:00 on 1/09/2015 and for 08:00 and 10:00 on 2/09/2015 indicated a marked improvement between the first two treatments was documented. On physiotherapy assessment of the chest the next day (2/09/2014), the chest wall symmetry improved and auscultation revealed normal breath sounds throughout the right and left lung with no added sounds as Table 1.

Table 1: Arterial blood gas results.

\begin{tabular}{|c|c|c|c|c|c|c|}
\hline & \multicolumn{3}{|c|}{ 01-09-2015 } & \multicolumn{2}{c|}{ 02-09-2015 } \\
\hline & $\mathbf{0 8 : 3 0}$ & $\mathbf{1 0 : 0 0}$ & $\mathbf{1 2 : 0 0}$ & $\mathbf{1 6 : 0 0}$ & $\mathbf{0 8 : 0 0}$ & $\mathbf{1 0 : 0 0}$ \\
\hline $\mathrm{pH}$ & 7.3 & 7.3 & 7.37 & 7.47 & 7.46 & 7.47 \\
\hline $\begin{array}{c}\mathrm{PaCO}_{2} \\
\left(\mathrm{mmHg}^{2}\right.\end{array}$ & 40 & 42.7 & 44.9 & 33.9 & 40.8 & 36.4 \\
\hline $\begin{array}{c}\mathrm{PaO}_{2} \\
\left(\mathrm{mmHg}^{2}\right.\end{array}$ & 288 & 260 & 125 & 162 & 135 & 145 \\
\hline $\begin{array}{c}\mathrm{HCO}_{3} \\
(\mathrm{~mol} / \mathrm{L})\end{array}$ & 29.4 & 24.8 & 25.3 & 24.6 & 29 & 26.4 \\
\hline $\mathrm{BE}$ & 2.9 & 0.1 & 0.3 & 1.7 & 5 & 3.2 \\
\hline
\end{tabular}

\section{Discussion}

The use of manual chest physiotherapy with postural drainage position proved to be beneficial to this patient with regards to re-inflation of the col-lapsed lung and improved oxygenation and ventilation. However, incentive spirometry training has an added advantage of improving the respiratory muscle strength. The cause of the atelectasis is speculated to be aspiration. Many patients have sudden detoriation in the ward as aspiration is an unexplained event happens in patients with respiratory complication and much attention have been needed for this patient population. At the time of writing this case assessment (four weeks later), the patient had regained a normal level of respiratory muscle functioning.

\section{Summary}

There is an improvement in oxygenation after the first treatment and the resolution of the atelectasis of the right and left lung within 20 hours, indicates the effective-ness of early physiotherapy treatment for patients with atelectasis with the help of incentive spirometer training. The findings of this case report confirm results from previous studies regarding the effectiveness of incentive spirometer as an adjunct to chest physiotherapy treatment and the effectiveness of physiotherapy management of patients with the help of incentive spirometer training as expiratory muscle training device has been facilitated in this study. 


(C) (1) $\begin{aligned} & \text { This work is licensed under Creative } \\ & \text { Commons Attribution 4.0 License } \\ & \text { DOI: } 10.19080 / J Y P .2018 .05 .555670\end{aligned}$

\section{Your next submission with Juniper Publishers} will reach you the below assets

- Quality Editorial service

- Swift Peer Review

- Reprints availability

- E-prints Service

- Manuscript Podcast for convenient understanding

- Global attainment for your research

- Manuscript accessibility in different formats

( Pdf, E-pub, Full Text, Audio)

- Unceasing customer service

Track the below URL for one-step submission https://juniperpublishers.com/online-submission.php 